\title{
Effect of 4 years of growth hormone therapy in children with Noonan syndrome in the American Norditropin Studies: Web-Enabled Research (ANSWER) Program ${ }^{\circledR}$ registry
}

Peter A Lee ${ }^{1 *}$, Judith Ross ${ }^{2}$, John A Germak ${ }^{3}$ and Robert Gut ${ }^{3}$

\begin{abstract}
Background: Noonan syndrome (NS) is a genetic disorder characterized by phenotypic features, including facial dysmorphology, cardiovascular anomalies, and short stature. Growth hormone $(\mathrm{GH})$ has been approved by the United States Food and Drug Administration for short stature in children with NS. The objective of this analysis was to assess the height standard deviation score (HSDS) and change in HSDS ( $\triangle H S D S)$ for up to 4 years (Y4) of GH therapy in children with NS.

Methods: The American Norditropin Studies: Web-Enabled Research (ANSWER) Program ${ }^{\circledR}$, a US-based registry, collects long-term efficacy and safety information on patients treated with Norditropin ${ }^{\circledR}$ (somatropin rDNA origin, Novo Nordisk A/S) at the discretion of participating physicians. A total of 120 children (90 boys, 30 girls) with NS, naïve to previous $\mathrm{GH}$ treatment, were included in this analysis.

Results: The mean (SD) baseline age of subjects $(n=120)$ was 9.2 (3.8) years. Mean (SD) HSDS increased from -2.65 (0.73) at baseline to $-1.32(1.11)$ at $Y 4(n=17)$. Subjects showed continued increase in HSDS from baseline to $Y 4$ without significant differences between genders at $Y 1$ or $Y 2$. The mean (SD) GH dose was 47 (11) mcg/kg/day at baseline and 59 (16) mcg/kg/day at $Y 4$. There was a negative correlation between baseline age and $\Delta H S D S$ at $Y 1$ $(R=-0.3156 ; P=0.0055)$ and $Y 2(R=-0.3394 ; P=0.017) . \Delta H S D S$ at $Y 1$ was significantly correlated with $\Delta H S D S$ at $Y 2$ $(n=37 ; R=0.8527, P<0.0001)$ and $Y 3(n=20 ; R=0.5145 ; P=0.0203)$, but not $Y 4(n=12 ; R=0.4066, P=0.1896)$.
\end{abstract}

Conclusions: GH treatment-naïve patients with NS showed continued increases in HSDS during 4 years of treatment with $\mathrm{GH}$ with no significant differences between genders up to 2 years. Baseline age was negatively correlated with $\triangle H S D S$ at $Y 1$ and $Y 2$. Whether long-term therapy in NS results in continued increase in HSDS to adult height remains to be investigated.

Trial registration: ClinicalTrials.gov NCT01009905

Keywords: Growth hormone, Noonan Syndrome, Somatropin, Short stature, Body height, Treatment outcome

\footnotetext{
* Correspondence: plee@psu.edu

'Department of Pediatrics, The Milton S. Hershey Medical Center, Penn State

College of Medicine, Hershey, PA, USA

Full list of author information is available at the end of the article
} 


\section{Introduction}

Noonan syndrome (NS), a genetic disorder first described by Noonan and Ehmke in 1963 [1], is characterized by phenotypic features including facial dysmorphology, cardiovascular anomalies, and short stature [2]. Patients with NS are typically born with appropriate size for gestational age, but reach median adult heights of only $162.5 \mathrm{~cm}$ and $152.7 \mathrm{~cm}$ for men and women, respectively, values that are approximately 2 SDS below the normal population [3]. While the etiology of short stature in NS patients is not definitively known, growth hormone (GH) therapy has been shown to improve growth rates [4]. This improvement in both growth rates and adult height is attributed, at least in part, to increased production of insulin-like growth factor 1 (IGF-1) [5]. Treatment with GH therapy has been shown to normalize height standard deviation scores (HSDSs) during childhood for patients with NS [6,7].

Despite the successful gain in height associated with GH therapy, response to treatment often varies. For many patients, factors such as GH dose and age at start of treatment may affect the outcome of GH therapy [8]. Furthermore, the success of GH therapy for patients with NS may also be influenced by the genetic causes of the disorder, although genetic mutations have not been identified in all patients with NS [9]. Currently identified genetic mutations explain approximately $60 \%$ of NS cases [10]. Genetic mutations associated with the NS phenotype are involved in the Ras/MAPK (mitogen-activated protein kinase) signal transduction pathway $[10,11]$. Several candidate genes involved in the Ras/MAPK signaling pathway have been identified, with the protein tyrosine phosphatase non-receptor type 11 gene (PTPN11) responsible for the greatest number of cases $[10,11]$.

In 2007, the United States (US) Food and Drug Administration (FDA) approved the use of $\mathrm{GH}$ for short stature in children with NS [12]. While this FDA approval is relatively recent, NS patients have been receiving GH therapy in clinical trials for a number of years, and the results of these trials have been published [2,4,7,13-18]. Since 2002, the American Norditropin Studies: Web-Enabled Research (ANSWER) Program ${ }^{\circledR}$ registry, which utilizes the enhanced research Webbased platform, NovoNet ${ }^{\circledR}$, has been collecting longterm efficacy and safety data on patients treated with Norditropin ${ }^{\circledR}$ (somatropin rDNA origin, Novo Nordisk $\mathrm{A} / \mathrm{S}$ ) in the United States. The use of Norditropin in patients within the ANSWER Program and participation in the registry is at the discretion of the contributing physician investigators and patient informed consent and includes additional diagnostic conditions that warrant treatment with GH. Also, completeness of data concerning patients (e.g. background histories and physical examination data, and additional findings from history and examination in addition to short stature, such as cardiac and skeletal problems) may vary. Recently, data from the ANSWER Program registry was used to assess the impact of gender, puberty, and age on change in height standard deviation scores ( $\triangle$ HSDSs) following 2 years of GH treatment across many diagnostic categories, including GH deficiency, multiple pituitary hormone deficiency, Turner syndrome, small for gestational age, NS, and idiopathic short stature [19]. The study showed that increase in HSDS could be achieved for all diagnostic categories, particularly when treatment was initiated at an early age. In the present analysis, data from the ANSWER Program registry are assessed to determine HSDS and $\triangle$ HSDS during up to 4 years of GH therapy in children with NS.

\section{Objective and methods}

The ANSWER Program is a US-based registry that has collected long-term efficacy and safety information for GH treatment-naïve and non-naïve patients treated with Norditropin since 2002 (NCT01009905). Patients' medical histories and physical examination data were entered by participating physician investigators using the NovoNet Web-based data entry tool. At the initial visit, study investigators collected baseline HSDS, weight, pretreatment bone age, maximal stimulated serum GH concentration, and serum IGF-1 concentrations. The data collected at followup clinical visits included GH dose/frequency, height, weight, IGF-1 concentration, and bone age. Dosing was determined by the treating physician.

Although both GH-naïve and non-naïve patients are included in the ANSWER Program registry, data from only GH-treatment-naïve patients (aged $\leq 18$ years) with NS were included in the current analysis. Potential subjects were excluded from the analysis if key variables had baseline or subsequent values that were deemed physically or chronologically implausible. Cross-sectional data from baseline, at year 1 (Y1), year 2 (Y2), year 3 (Y3), and year 4 (Y4) were analyzed. Data at each post-baseline time point were collected within a \pm 3 -month window. Baseline data were summarized, including gender, age, HSDS, IGF-1 standard deviation score (IGF-1 SDS), bone age, and maximal stimulated serum GH concentration. HSDS ( $\mathrm{z}$ score) was calculated according to the standard formulas provided by the Centers for Disease Control and Prevention [20]. Target height was calculated using the following formula: [average of the parents' heights] $+6.5 \mathrm{~cm}$ for males and [average of the parents' heights] $-6.5 \mathrm{~cm}$ for females. Target height SDS is calculated according to the standard formulas provided by the CDC. HSDS corrected for target height, [height SDS at each visit] - [target height SDS], was determined annually. Change in HSDS ( $\triangle$ HSDS) was compared between gender groups using least squares 
means estimates from an analysis of covariance (ANCOVA) model with gender as fixed effect and baseline HSDS value as a covariate. For analyses of age at start of treatment, age ranges were defined to be $<11$ or $\geq 11$ years of age for boys, and $<10$ or $\geq 10$ years of age for girls. These ages were chosen so that both younger age categories would be comprised primarily of pre-pubertal individuals. Statistical comparisons of $\triangle$ HSDS between age groups stratified by gender were conducted using $t$-tests. Linear regression was performed to identify the relationship between $\triangle$ HSDS after 1 or 2 years of $\mathrm{GH}$ treatment and age at start of treatment. Data following 3 or 4 years of treatment were not analyzed for logistic regression due to a limited number of patients. The corresponding Pearson correlation coefficients (R) were calculated along with the $\mathrm{p}$ values for testing their significance. Mean GH dose at each time point was summarized. Analyses were performed to evaluate (1) whether $\triangle$ HSDS during the first year of therapy was predictive of $\triangle \mathrm{HSDS}$ at later time points (linear regression analysis), (2) whether baseline IGF-I or baseline IGF-I SDS was predictive of $\triangle$ HSDS (linear regression analysis), and (3) whether $\triangle$ HSDS differed for GH-deficient versus $\mathrm{GH}$-sufficient patients (deficient $\mathrm{GH}$ status was defined as GH peak at baseline $<10$; $\Delta$ HSDS was compared between groups using $t$-tests).

\section{Results}

\section{Baseline demographics and patient disposition}

The ANSWER Program registry contained information for 120 children (90 boys and 30 girls) with NS. The mean (SD) baseline age of all children with NS was 9.2 (3.8) years; the mean age for boys and girls was similar. All patients in the younger age groups (ie, boys $<11$ years and girls $<10$ years) were Tanner stage 1 . Other characteristics are summarized in Table 1. Mean (SD) maximal $\mathrm{GH}$ level was $11.7(8.4) \mathrm{ng} / \mathrm{ml}(\mathrm{n}=34)$ with range of 0.8 to $39.3 \mathrm{ng} / \mathrm{ml}$, while mean (SD) IGF-1 SDS of -3.0 (1.5) indicated low IGF-1 levels $(n=73)$. The numbers of patients that completed $1,2,3$, and 4 years of treatment were $76,49,31$, and 17 , respectively.

\section{The effects of GH treatment on HSDS}

The mean (SD) GH dose for the NS patients was 47 (11) $\mathrm{mcg} / \mathrm{kg} /$ day at baseline, 52 (12) $\mathrm{mcg} / \mathrm{kg} /$ day after 1 year of treatment, $49(15) \mathrm{mcg} / \mathrm{kg} /$ day after 2 years of treatment, 54 (19) $\mathrm{mcg} / \mathrm{kg} /$ day after 3 years of treatment, and 59 (16) $\mathrm{mcg} / \mathrm{kg} /$ day after 4 years of treatment. Among patients with 4 years of longitudinal data $(n=7)$, the mean (SD) GH dose was 46 (3) $\mathrm{mcg} / \mathrm{kg} /$ day at baseline, $53(11) \mathrm{mcg} / \mathrm{kg} /$ day at 2 years, 57 (15) at 2 years, 58 (19) $\mathrm{mcg} / \mathrm{kg} /$ day at 3 years, and 63 (16) at 4 years. The overall effects of GH treatment on patients with NS are summarized in Figure 1. Cross-sectional data show that
Table 1 Baseline Demographics

\begin{tabular}{lcccc}
\hline Characteristic & N & Mean (SD) & Median & Range \\
\hline Age, years & & & & \\
\hline \multicolumn{1}{c}{ All subjects } & 120 & $9.2(3.8)$ & 9.6 & $1.6,16.9$ \\
\hline \multicolumn{1}{c}{ Boys } & 90 & $9.20(4.09)$ & 9.6 & $1.6,16.9$ \\
\hline Girls & 30 & $9.24(2.98)$ & 9.6 & $2.8,14.2$ \\
\hline HSDS & & & \\
\hline \multicolumn{1}{c}{ All subjects } & 120 & $-2.6(0.7)$ & -2.6 & $-4.5,-1.2$ \\
\hline \multicolumn{1}{c}{ Boys } & 90 & $-2.6(0.74)$ & -2.44 & $-4.5,-1.2$ \\
\hline \multicolumn{1}{c}{ Girls } & 30 & $-2.9(0.67)$ & -2.88 & $-4.1,-1.7$ \\
\hline Target HSDS & 99 & $-0.3(0.9)$ & -0.2 & $-3.8,2.0$ \\
\hline IGF-1 SDS & 73 & $-3.0(1.5)$ & -2.8 & $-8.2,0.6$ \\
\hline Bone age, years & 93 & $7.7(3.8)$ & 7.8 & $0.5,15.5$ \\
\hline Maximal GH, ng/ml & 34 & $11.7(8.4)$ & 10.0 & $0.8,39.3$ \\
\hline BMl & 120 & $16.4(2.0)$ & 16.1 & $13.2,26.9$ \\
\hline Weight, kg & 120 & $23.9(9.4)$ & 22.8 & $8.3,51.6$ \\
\hline BMl, body mas $\mathrm{nndex}$ GH
\end{tabular}

$B M I$, body mass index; $G H$, growth hormone; $H S D S$, height standard deviation score; $S D$, standard deviation.

mean (SD) HSDS increased from -2.65 (0.73) at baseline to $-1.32(1.11)$ after 4 years of treatment (Figure 1A). Mean (SD) HSDS corrected for target height, was -2.4 (1.02) at baseline, $-2.0(1.09)$ at $\mathrm{Y} 1(\mathrm{n}=64),-1.5(1.22)$ at Y2 $(\mathrm{n}=42),-1.5(1.24)$ at $Y 3(\mathrm{n}=29)$, and $-1.0(1.50)$ at Y4 $(\mathrm{n}=14)$. Among the 7 patients for whom 4 years of longitudinal data were available, mean (SD) HSDS was $-2.48(0.76)$ at baseline, $-2.29(0.78)$ after 1 year of treatment, $-1.88(1.08)$ after 2 years of treatment,-1.54 (1.23) after 3 years of treatment, and -1.22 (1.24) after 4 years of treatment (Figure 1B). Following 4 years of GH treatment 12 of 17 patients (71\%) achieved height normal for age and gender (defined as HSDS > -2SD).

Patient gender did not significantly affect the outcome of GH therapy for patients with NS. Mean (SD) HSDS increased progressively from baseline for both boys and girls. Comparisons from the ANCOVA model showed no significant differences between boys and girls after 1 or 2 years treatment. On the contrary, patient age at onset of therapy did affect outcome of GH therapy. There was a significant negative correlation between baseline age and change in HSDS after 1 year $(n=76$; correlation coefficient $\mathrm{R}=-0.3156 ; \mathrm{P}=0.0055)$ and 2 years of treatment $(n=49 ; R=-0.3394 ; P=0.017)$ (Figure 2). Among boys, there was a significantly greater $\Delta$ HSDS from baseline for the younger age group versus the older age group after 1 and 2 years of treatment; no significant differences were observed among girls at either time point, which may reflect the lower number of female patients (Table 2).

Although the number of children with post-baseline IGF-1 SDS data was limited, mean (SD) IGF-1 SDS increased from a value of -2.96 (1.55) at baseline $(n=73)$ to $-1.35(2.31)$ after 1 year of treatment $(n=17)$, 


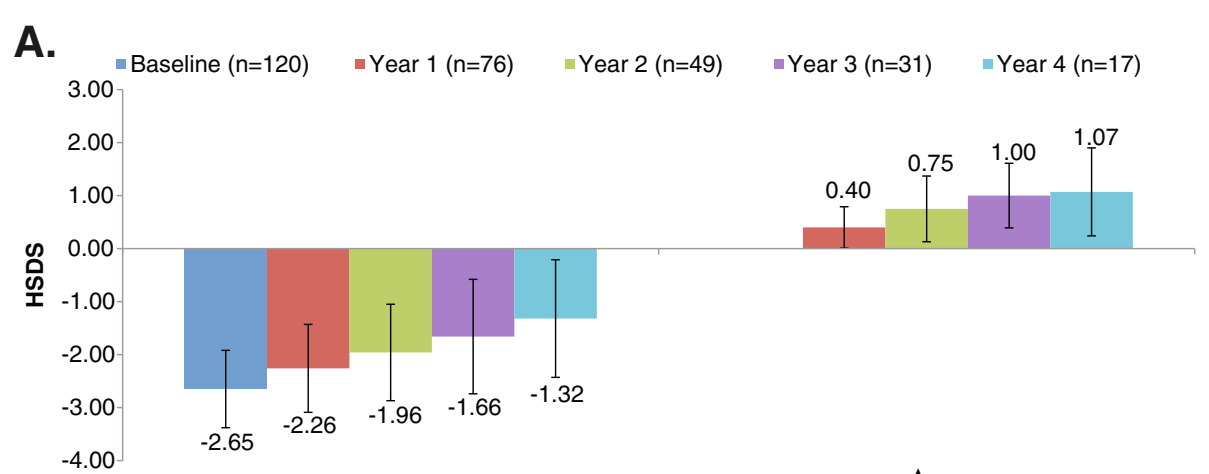

Height SDS

$\Delta$ HSDS

B.

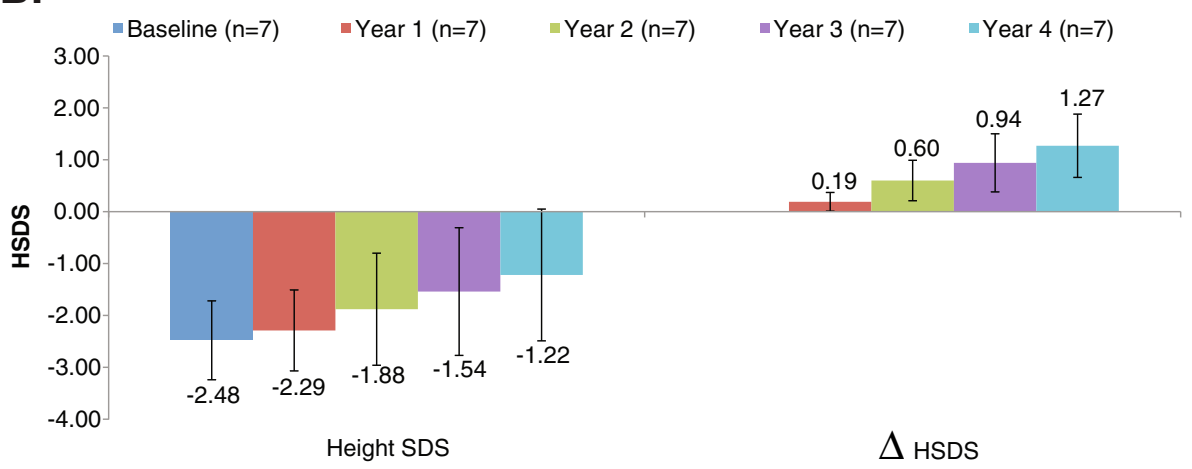

Figure 1 Mean HSDS Change at Year 1, Year 2, Year 3, and Year 4: (A) Cross-sectional Data and (B) Longitudinal Data. HSDS, height standard deviation score.

-0.87 (2.79) after 2 years of treatment $(\mathrm{n}=12),-0.02$ (1.08) after 3 years of treatment $(n=7)$, and $0.22(2.62)$ after 4 years of treatment $(n=5)$. Mean (SD) weight increased from baseline following 4 years of treatment, whereas body mass index (BMI) remained stable (Figure 3). The small magnitude of the change in BMI suggests that increases in weight were proportional to increases in height.

Several analyses were performed to examine early potential predictors of later response. $\triangle$ HSDS at Year 1 was significantly correlated with $\triangle \mathrm{HSDS}$ at Year $2(\mathrm{n}=37$; $\mathrm{R}=0.8527, \mathrm{P}<0.0001)$ and Year $3(\mathrm{n}=20 ; \mathrm{R}=0.5145$; $\mathrm{P}=0.0203)$, but not Year $4(\mathrm{n}=12 ; \mathrm{R}=0.4066, \mathrm{P}=0.1896)$. Neither baseline IGF-1 levels nor baseline IGF-1 SDS were predictive of $\triangle$ HSDS (data not shown). GH-deficient patients $(n=16)$ tended to have greater $\triangle$ HSDS than GHsufficient patients $(n=18)$; the difference was statistically significant only at Year 2 (GH-deficient: $\mathrm{n}=7$, mean [SD] $\triangle$ HSDS: 1.08 [0.66] vs GH-sufficient: $\mathrm{n}=13$, mean [(SD] $\Delta$ HSDS: $0.40[0.56] ; \mathrm{P}=0.0266)$.

\section{Discussion}

Results from this 4-year analysis of GH therapy of NS subjects from the ANSWER Program registry demonstrate an increase in HSDS over the course of treatment.
The mean HSDS $(n=120)$ at start of treatment was -2.6 . By the end of 3 years of GH therapy, mean HSDS had increased to $-1.66(n=31)$, and by the end of 4 years to $-1.32(n=17)$. This increase in mean HSDS is similar to data from a clinical trial conducted by MacFarlane et al., in which HSDS (SD) of NS patients $(n=23)$ increased from $-2.7(0.4)$ at the start of GH therapy to -1.9 (0.9) following 3 years of treatment [15]. Our findings are consistent with, and perhaps better than, results from the National Cooperative Growth Study (NCGS), which reported an increase in HSDS from -3.3 (0.9) at baseline to $-2.4(1.1)$ at 3 years and -2.1 (1.2) at 4 years $(n=42)$ [4], and to the Pharmacia \& Upjohn International Growth Study (KIGS), which reported an increase from $-2.9(0.7)$ at baseline to approximately -2.3 at 4 years $(n=25)$ [14]. We also found an increase in HSDS corrected for target height from -2.4 (1.02) at baseline to $-1.0(1.50)$ at Y4.

Furthermore, for patients for whom longitudinal data were available $(n=7)$, mean HSDS increased consistently over the 4 years of treatment, indicating that $\mathrm{GH}$ therapy of NS patients results in sustained growth over multiple years of treatment. The yearly incremental change in mean HSDS for these patients was 0.19, 0.41, 0.34, and 0.32 for $\mathrm{Y} 1, \mathrm{Y} 2, \mathrm{Y} 3$, and Y4 respectively. This trend of 

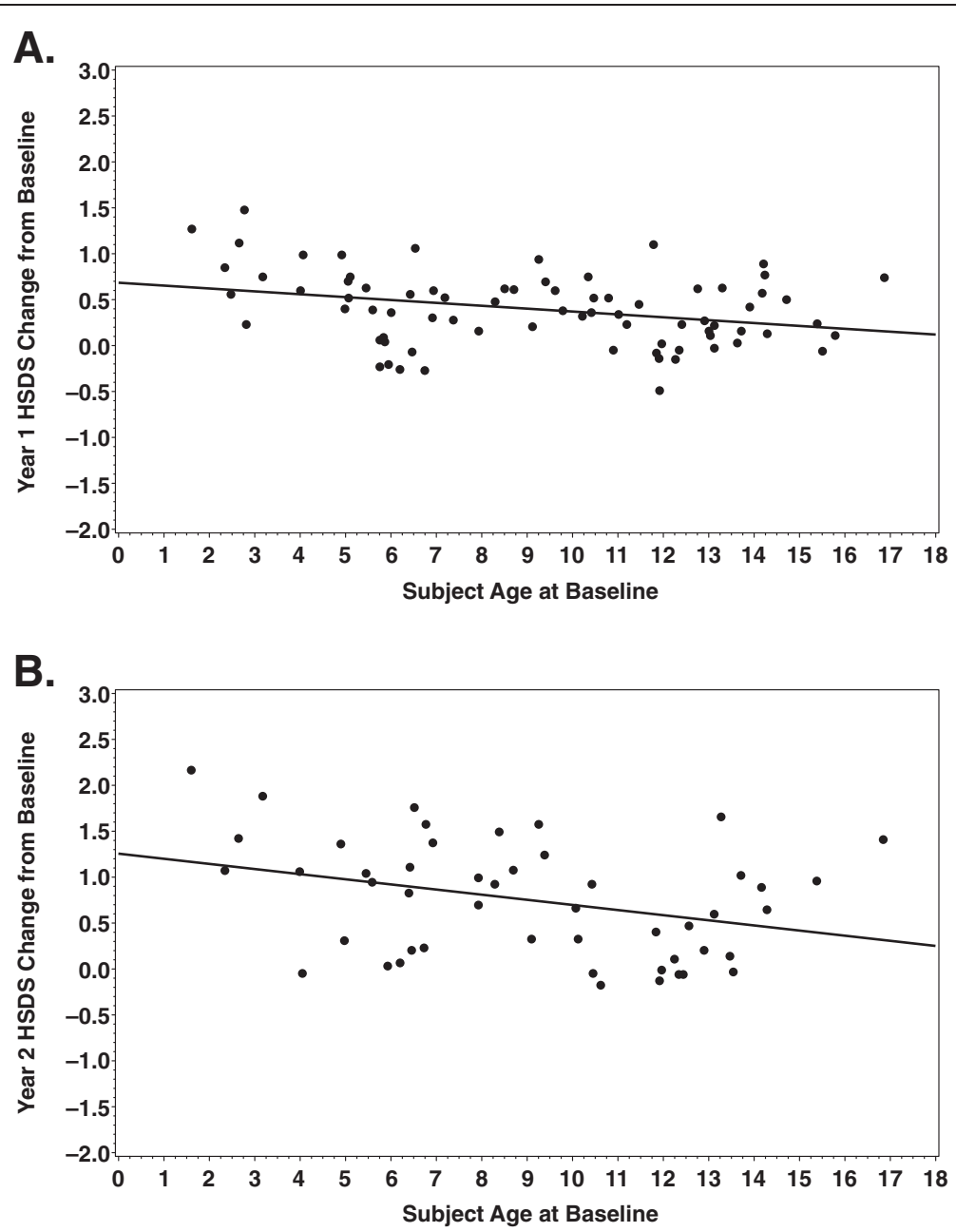

Figure 2 Linear Regression of $\Delta$ HSDS at Year 1 and Year 2 on Baseline Age. At both $(\mathbf{A})$ Year $1(n=76$; correlation $=-.3156 ; P=0.0055)$ and (B) Year $2(n=49$; correlation $=-.3394 ; P=0.017)$, there was a significant negative correlation between $\Delta H S D S$ and baseline age (ie, $\Delta H S D S$ decreased as baseline age increased).

sustained growth is consistent with a previous registrybased study conducted by Romano et al. In 1996, the group analyzed data of 150 children with NS who were enrolled in the NCGS [4]. For the 42 children in the study who were monitored for at least 4 years of $\mathrm{GH}$

Table 2 HSDS Change from Baseline Stratified by Age at Treatment Start and by Gender

\begin{tabular}{|c|c|c|c|c|c|}
\hline \multicolumn{3}{|c|}{ Boys } & \multicolumn{3}{|c|}{ Girls } \\
\hline$<11$ years & $\geq 11$ years & & $<10$ years & $\geq 10$ years & \\
\hline N Mean (SD) & ) N Mean (SD) & P value & N Mean (SD) & ) N Mean (SD) & $P$ value \\
\hline Y1 320.53 (0.36) & $220.24(0.34)$ & 0.0046 & $120.42(0.51)$ & $100.29(0.38)$ & 0.5159 \\
\hline Y2 $250.94(0.65)$ & $130.47(0.50)$ & 0.0284 & $60.77(0.55)$ & $50.49(0.67)$ & 0.4726 \\
\hline Y3 $160.92(0.65)$ & $101.01(0.65)$ & 0.7168 & $21.24(0.33)$ & $31.24(0.45)$ & 0.9968 \\
\hline Y4 $61.15(0.93)$ & $80.90(0.88)$ & 0.6082 & $21.34(0.78)$ & $1.52(-)$ & - \\
\hline
\end{tabular}

therapy, yearly incremental change in mean HSDS was $0.5,0.2,0.2$, and 0.3 for Y1, Y2, Y3, and Y4 of treatment, respectively, with some patients exceeding their predicted height by the end of treatment..

However, even after 4 years of GH therapy, 29\% (5/17) of patients remained short for age and gender (as defined by $\mathrm{HSDS}<-2 \mathrm{SD}$ ). Possible reasons for this could include an innate resistance to GH therapy among some with NS or advanced bone age/chronologic age at treatment start. Without treatment, height in NS follows the 3rd percentile during the first several years of life, and then generally declines further at puberty, with mean final height approximately 2 SDS below normal limits [3,21].

The mean increase in HSDS was similar for boys and girls in this study, suggesting that gender does not significantly affect the outcome of treatment. This trend differs from previous clinical trial studies in which 


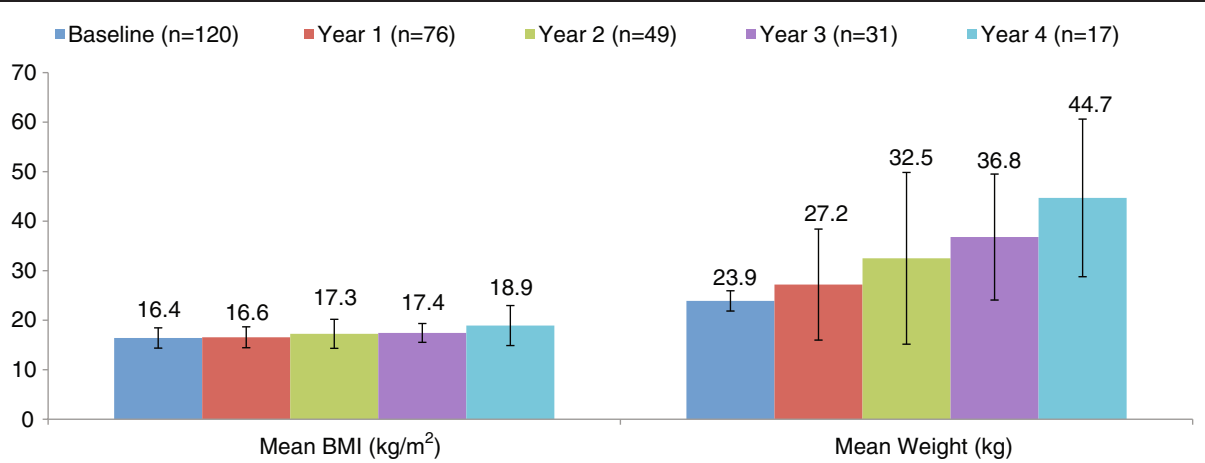

Figure 3 Mean BMI and Weight Change at Year 1, Year 2, Year 3, and Year 4 (Cross-sectional Data). BMI, body mass index.

gender was shown to affect the outcome of GH therapy in patients with NS $[6,16]$.

In contrast to what was observed in this analysis, previous registry-based studies have assessed the short- and long-term effects of GH therapy in patients with NS and found that the increase in height of NS patients treated with GH therapy is highest after 1 year, but wanes in subsequent years of treatment. In 2001, Kirk et al. conducted an analysis of NS patients involved in the KIGS study [14]. The yearly incremental change in HSDS for these patients waned significantly after 1 year of treatment. Mean HSDS increased by 0.3 over the first year, but further increase was not observed over the next 4 years. A similar trend was observed by Raaijmakers, et al., who analyzed the growth response in $402 \mathrm{NS}$ patients enrolled in the KIGS database who were treated with GH therapy [18]. After 1 year of treatment, mean HSDS increased by 0.54 , but the incremental increases were significantly lower (0.13 and 0.13) following years 2 and 3 of GH therapy. Finally, in the clinical trial conducted by MacFarlane et al., $\triangle$ HSDS was 0.5 during the first year of treatment, but the yearly incremental increase in mean HSDS dropped to 0.1 and 0.2 for the second and third years of treatment, respectively. It was confirmed in the MacFarlane clinical trial that the lower incremental increase in HSDS for years 2 and 3 of treatment could not be attributed to reduced growth rate caused by non-adherence to therapy [15]. Potential explanations for waning growth may be related to older age at treatment onset, GH sufficiency status, GH dosage, and the presence of other genetic findings specific to NS. The presence of a specific mutation may be a factor in the response to GH treatment, although the type of mutation does not necessarily correlate with the severity of short stature or the patient's response to GH therapy [16,22-25]. In the current study, the incremental gain in HSDS among the 7 patients for whom longitudinal data were available was lowest during Year 1. The mean GH dose among these patients increased each year, which may explain, in part, why the incremental gains were higher after Year 1.
The mean (SD) weight determined for the patients enrolled in the ANSWER Program registry increased from 23.9 (9.4) $\mathrm{kg}$ at baseline to 44.7 (15.9) $\mathrm{kg}$ following 4 years of treatment, whereas body mass index (BMI) remained stable. The small magnitude of the change in BMI suggests that increases in weight were proportional to increases in height, indicating that GH therapy for NS patients did not significantly impact body composition in ways unrelated to linear growth. Although the number of children with post-baseline IGF-1 SDS data was limited, analysis of the available data showed that mean (SD) IGF-1 SDS increased. Previous studies have indicated a positive linear relationship between the change in IGF-1 and $\triangle$ HSDS for patients undergoing GH treatment [26].

In addition to sustained growth over the course of $\mathrm{GH}$ treatment, and a positive correlation between $\triangle$ HSDS at Year 1 and $\triangle$ HSDS at Years 2 and 3, analysis of data from boys and girls in the ANSWER Program registry also showed that a negative correlation exists between the age at the start of treatment and $\triangle$ HSDS (Figure 2). That is, $\triangle$ HSDS decreased as age at initiation of treatment increased. In an analysis using age 11 as a cutoff for younger versus older age, boys who began treatment before the age of 11 years showed a mean $\triangle$ HSDS of 0.53 after 1 year of treatment and 0.94 after 2 years (Table 2). On the other hand, when treatment was initiated for boys at an age greater than 11 years, mean $\triangle$ HSDS was only 0.24 after 1 year $(\mathrm{P}=0.046)$ and 0.47 after 2 years $(P=0.0284)$. The same trend was observed for girls in this study, although differences were not statistically significant. Although the age cut-offs of 11 years for boys and 10 years for girls did correspond to baseline pubertal stage (ie, all patients in the younger age groups were pre-pubertal), the relative contribution of the accelerated growth rate during the pubertal growth spurt is unclear. A similar pattern was observed by Romano et al. in data from the NCGS [7], which showed that greater near adult height (NAH) for NS patients was associated with earlier initiation and longer duration of GH therapy. 
These results emphasize the importance of early diagnosis and initiation of therapy for optimal height outcomes. However, diagnosing NS is a difficult task, even for many specialists, due to the fact that it is primarily based on clinical features. Therefore, the Noonan Syndrome Support Group recently coordinated a conference comprised of professionals with extensive knowledge of various aspects of the disease to develop guidelines for the diagnosis and management of the disorder [10]. These guidelines provide pediatricians and other healthcare professionals with a comprehensive description of genetic factors associated with NS and key clinical features of the disorder.

One limitation of the current study is the lack of data regarding the underlying genetic defect, particularly the presence or absence of the PTPN11 mutation, responsible for causing NS in these patients. Nonetheless, this analysis provides valuable information, such as expectations for treatment outcomes and the potential to optimize growth by initiating GH treatment early, which can help to guide clinicians who treat patients with NS.

In conclusion, this analysis of the ANSWER Program registry shows that continued increase in HSDS after 4 years of treatment with $\mathrm{GH}$ could be achieved in GHnaïve subjects with NS, with no significant differences in treatment outcome between genders at years 1 and 2 . The data also show that baseline age was negatively corty related with $\triangle$ HSDS following 1 and 2 years of treatment. Whether longer-term therapy will have a beneficial effect on adult height remains to be investigated.

\section{Competing interests}

$\mathrm{PL}$ : Has participated in patient registries of growth hormone treated patients supported by Genentech, Eli Lilly and Pfizer.

JR: Has participated in patient registries of growth hormone treated patients supported by Genentech, Eli Lilly and Pfizer. JR is a consultant for Eli Lilly, Pfizer and Novo Nordisk Inc

JG: Is an employee of Novo Nordisk Inc and as such has received stock/stock options.

RG: Is an employee of Novo Nordisk Inc and as such has received stock/stock options.

\section{Authors' contributions}

$\mathrm{PL}$ and JR were primary investigators and interpreted the data, critically reviewed and suggested revisions for manuscript drafts, and approved final draft. JG and RG contributed to the acquisition of data, provided analysis and interpretation the data, critically reviewed draft, and approved final draft. All authors read and approved the final manuscript.

\section{Acknowledgement}

The authors wish to thank Emma Hitt and Sherri D. Jones, PharmD of MedVal Scientific Information Services, LLC, for providing medical writing and editorial assistance. This manuscript was prepared according to the International Society for Medical Publication Professionals' Good Publication Practice for Communicating Company-Sponsored Medical Research: the GPP2 Guidelines. Funding to support the preparation of this manuscript was provided by Novo Nordisk Inc.

\section{Author details}

${ }^{1}$ Department of Pediatrics, The Milton S. Hershey Medical Center, Penn State College of Medicine, Hershey, PA, USA. ²DuPont Hospital for Children, Department of Pediatrics, Thomas Jefferson University, Philadelphia, PA, USA.
${ }^{3}$ Novo Nordisk Inc., Department of Clinical Development, Medical and Regulatory Affairs, Princeton, NJ, USA.

Received: 28 December 2011 Accepted: 8 June 2012

Published: 8 June 2012

\section{References}

1. Noonan JA, Ehmke DA: Associated non-cardiac malformations in children with congenital heart disease. J Pediatr 1963, 63:468-470.

2. Noordam C, van der Burgt I, Sweep CG, Delemarre-van de Waal HA, Sengers RC, Otten BJ: Growth hormone treatment in children with Noonan's syndrome: four year results of a partly controlled trial. Acta Paediatr 2001, 90(8):889-894.

3. Ranke MB, Heidemann P, Knupfer $C$, Enders $H$, Schmaltz AA, Bierich JR: Noonan syndrome: growth and clinical manifestations in 144 cases. Eur J Pediatr 1988, 148(3):220-227.

4. Romano AA, Blethen SL, Dana K, Noto RA: Growth hormone treatment in Noonan syndrome: the National Cooperative Growth Study experience. J Pediatr 1996, 128(5 (pt 2):S18-S21.

5. Gharib H, Cook DM, Saenger PH, Bengtsson BA, Feld S, Nippoldt TB, Rodbard HW, Seibel JA, Vance ML, Zimmerman D, Palumbo PJ, Bergman DA, Garber JR, Hamilton CR Jr, Petak SM, Rettinger HI, Service FJ, Shankar TP, Stoffer SS, Tourletot JB: American Association of Clinical Endocrinologists medical guidelines for clinical practice for growth hormone use in adults and children - 2003 update. Endocr Pract 2003, 9(1):64-76.

6. Osio D, Dahlgren J, Wikland KA, Westphal O: Improved final height with long-term growth hormone treatment in Noonan syndrome. Acta Paediatr 2005, 94(9):1232-1237.

7. Romano AA, Dana K, Bakker B, Davis DA, Hunold JJ, Jacobs J, Lippe B: Growth response, near-adult height, and patterns of growth and puberty in patients with Noonan syndrome treated with growth hormone. J Clin Endocrinol Metab 2009, 94(7):2338-2344.

8. Ranke MB: Noonan syndrome: growth to growth hormone - the experience of observational studies. Horm Res 2009, 72(suppl 2):36-40.

9. Binder G: Response to growth hormone in short children with Noonan syndrome: correlation to genotype. Horm Res 2009, 72(suppl 2):52-56.

10. Romano AA, Allanson JE, Dahlgren J, Gelb BD, Hall B, Pierpont ME, Roberts $A E$, Robinson W, Takemoto CM, Noonan JA: Noonan syndrome: clinical features, diagnosis, and management guidelines. Pediatrics 2010, 126(4):746-759.

11. Tartaglia M, Zampino G, Gelb BD: Noonan syndrome: clinical aspects and molecular pathogenesis. Mol Syndromol 2010, 1(1):2-26.

12. Norditropin ${ }^{\circledR}$ (somatropin [rDNA origin] injection) for subcutaneous use [prescribing information]: Princeton, NJ: Novo Nordisk; 2010

13. De SJ, Otten BJ, Francois I, Bourguignon JP, Craen M, Van BB I, Massa GG: Growth hormone therapy in pre-pubertal children with Noonan syndrome: first year growth response and comparison with Turner syndrome. Acta Paediatr 1997, 86(9):943-946.

14. Kirk JM, Betts PR, Butler GE, Donaldson MD, Dunger DB, Johnston DI, Kelnar CJ, Price DA, Wilton P, UK KIGS Executive Group: Group t: Short stature in Noonan syndrome: response to growth hormone therapy. Arch Dis Child 2001, 84(5):440-443.

15. MacFarlane CE, Brown DC, Johnston LB, Patton MA, Dunger DB, Savage MO, McKenna WJ, Kelnar CJ: Growth hormone therapy and growth in children with Noonan's syndrome: results of 3 years' follow-up. J Clin Endocrinol Metab 2001, 86(5):1953-1956.

16. Noordam C, Peer PG, Francois I, De Schepper J, Van BB I, Otten BJ: Longterm GH treatment improves adult height in children with Noonan syndrome with and without mutations in protein tyrosine phosphatase, non-receptor-type 11. Eur J Endocrinol 2008, 159(3):203-208.

17. Ogawa M, Moriya N, Ikeda H, Tanae A, Tanaka T, Ohyama K, Mori O, Yazawa T, Fujita K, Seino Y, Kubo T, Tanaka H, Nishi Y, Yoshimoto M: Clinical evaluation of recombinant human growth hormone in Noonan syndrome. Endocr J 2004, 51(1):61-68.

18. Raaijmakers R, Noordam C, Karagiannis G, Gregory JW, Hertel NT, Sipila I, Otten BJ: Response to growth hormone treatment and final height in Noonan syndrome in a large cohort of patients in the KIGS database. J Pediatr Endocrinol Metab 2008, 21(3):267-273.

19. Ross J, Lee PA, Gut R, Germak J: Factors influencing the one- and two-year growth response in children treated with growth hormone: analysis from an observational study. Int J Pediatr Endocrinol 2010, 2010:494656. 
20. Centers for Disease Control and Prevention: Percentile data files with LMS values; http://www.cdc.gov/growthcharts/percentile_data_files.htm.

21. Otten BJ, Noordam C: Growth in Noonan syndrome. Horm Res 2009, 72 (suppl 2):31-35.

22. Dahlgren J: GH therapy in Noonan syndrome: review of final height data. Horm Res 2009, 72(suppl 2):46-48.

23. Ferreira LV, Souza SA, Arnhold IJ, Mendonca BB, Jorge AA: PTPN11 (protein tyrosine phosphatase, nonreceptor type 11) mutations and response to growth hormone therapy in children with Noonan syndrome. J Clin Endocrinol Metab 2005, 90(9):5156-5160

24. Binder G, Neuer K, Ranke MB, Wittekindt NE: PTPN11 mutations are associated with mild growth hormone resistance in individuals with Noonan syndrome. J Clin Endocrinol Metab 2005, 90(9):5377-5381.

25. Limal JM, Parfait B, Cabrol S, Bonnet D, Leheup B, Lyonnet S, Vidaud M, Le BY: Noonan syndrome: relationships between genotype, growth, and growth factors. J Clin Endocrinol Metab 2006, 91(1):300-306.

26. Noordam C, van der Burgt I, Sweep CG, Delemarre-van de Waal HA, Sengers RC, Otten BJ: Growth hormone (GH) secretion in children with Noonan syndrome: frequently abnormal without consequences for growth or response to GH treatment. Clin Endocrinol (Oxford) 2001, 54(1):53-59.

doi:10.1186/1687-9856-2012-15

Cite this article as: Lee et al:: Effect of 4 years of growth hormone therapy in children with Noonan syndrome in the American Norditropin Studies: Web-Enabled Research (ANSWER) Program ${ }^{\circledR}$ registry.

International Journal of Pediatric Endocrinology 2012 2012:15.

\section{Submit your next manuscript to BioMed Central and take full advantage of:}

- Convenient online submission

- Thorough peer review

- No space constraints or color figure charges

- Immediate publication on acceptance

- Inclusion in PubMed, CAS, Scopus and Google Scholar

- Research which is freely available for redistribution 